\title{
El Sindicato Único de Mineros de Asturias (SUM) 1922-1935
}

\author{
Ceferino Álvarez
}

\section{RESUMEN}

El Sindicato Único de Mineros de Asturias (SUM), a pesar de su breve existencia (1922-1935), tuvo un peso notable en el movimiento obrero de Asturias. No obstante la historiografia analiza muy parcamente este movimiento, y generalmente parece

ignorarlo y despreciarlo frente al Sindicato de Obreros de Mineros de Asturias (SOMA), el Sindicato Minero por antonomasia. Un análisis de esta organización obrera permite reflejar las

actitudes de los mineros asturianos frente a los problemas laborales, sus posicionamientos acerca de la revolución rusa, así cómo estimar la influencia que tenía el Partido

Comunista en Asturias.

Se intenta responder a las preguntas:

¿Cómo y porque nació el SUM?, ¿Cuál fue su peso en los movimientos sociales asturianos de aquella época?,

¿En qué medida tenía poder de convocatoria de los mineros?, ¿Cuáles fueron sus principales logros?, ¿Por qué no logró una implantación más sostenida?

\section{ABSTRACT}

The Sindicato Unico de Mineros de Asturias - SUM- (The Trade Union of the Asturian Miners) in spite of its short life (1922 - 1935) had a considerable effect on the Workers' Movement in Asturias. However historic research has only superficially analysed this movement and in general has seemed to ignore and value it less than the Sindicato de Obreros de Mineros de Asturias - SOMA- (The Workers' Union of Miners of Asturias), the miners' trade union par excellance. An analysis of this workers' organization allows reflection concerning the attitudes of the Asturian miners with respect to labour problems, their position concerning the Russian Revolution and an estimation of the influence which the Communist Party had in Asturias.

An attempt is made to answer the following questions. How and why was the SUM created? How important was it in the social movements in Asturias at that time? To what extent did it have power to call the miners to strike? What were its main achievements? Why did it not last for a longer time? 
PALABRAS CLAVE: Movimiento obrero, sindicatos, Asturias.
KEY WORDS

Workers movement, Trade Unions, Asturias.

\section{¿CÓMO NACIÓ EL SUM?}

EI SUM es un componente más de la historia social de Asturias, y su estudio corresponde a un conocimiento sectorial así cómo a un análisis metodológico basado en la teoría de los modos de producción y al enfrentamiento de las clases sociales cómo factor fundamental en el proceso histórico. Las páginas de historia de aquella época, en aquellos lugares, y protagonizadas por los trabajadores de entonces, se inscriben en la historia social, entendida ésta cómo «tronco matriz de la ciencia histórica».

La revolución rusa provocó un fuerte impacto en el mundo laboral tanto en Asturias, cómo en España, y animó a los trabajadores a reivindicar mejores condiciones de trabajo y aumento de sueldos, aunque también luchaban por instaurar otro régimen social. Para lograrlo, se organizaron, apoyándose en las organizaciones internacionales, en Asociaciones, Partidos y Sindicatos. Éstos últimos obedecían a diferentes ideologías y fueron los impulsores de las reivindicaciones de los mineros.

\section{EL SINDICATO OBRERO DE MINEROS DE ASTURIAS Y LOS CONFLICTOS LABORALES}

Los movimientos reivindicativos de los mineros fueron continuos desde el principio de la industrialización de Asturias ${ }^{1}$. Las huelgas que tuvieron lugar hasta principios del siglo $\mathrm{xx}$, vieron frustradas sus aspiraciones para conseguir, tanto mejoras laborales, cómo incrementos salariales que les permitiesen unos progresos en su forma de vida. En mayo de 1890 estalló la huelga en las minas Molinescu y Lláscares de la Fábrica de Mieres, segundada por la mayoría de la minería asturiana. También hay que citar la huelga de enero de 1898 en Mieres, la de mayo en Sama, la de 1889 en Lieres y Tudela-Veguin, las de 1900 en Mieres y Turón. Las organizaciones que se implantaban eran destruidas durante las huelgas. El miedo instaurado por la patronal y sus policías provocaron la deserción de los sindicatos.

\footnotetext{
1 Santullano, G., Historia de la minería asturiana, Salinas, Ayalga, 1978, págs. 144 y siguientes.
} 
Los resultados que se lograron fueron escasos. La falta de organización por una parte, y la represión ${ }^{2}$ por la otra hacían que lanzarse a una huelga representase un riesgo demasiado alto para el trabajador quien se exponía a perder su trabajo, es decir, su único sustento.

Habrá que esperar hasta 1910, con la creación del Sindicato de Obreros Mineros de Asturias (SOMA) para que la clase obrera minera pueda disponer de una organización propia con una fuerza real. Llaneza, el creador y el alma del Sindicato, fue nombrado secretario del primer Comité ejecutivo formado, además, por José de la Fuente, Eusebio Marcos, Laureano Carril, Aquilino Baragaño y José Prieto, todos vecinos de Mieres, y J. Ramón Parrado y Manuel Fernández, provenientes de Turón.

Se constituyó así una organización sindical, no de oficio, pero de ramo productivo: la minería del carbón. En febrero de 1911, el SOMA se incorporó a la UGT, fortaleciendo con su presencia el movimiento socialista. EI SOMA fue un referente para la clase minera asturiana. Para Llaneza, la pertenencia al sindicato implicaba además del compromiso de modificar la sociedad en su conjunto, crear las condiciones para que el minero pueda desarrollarse intelectualmente, transformándose en hombres que piensen y actúen de manera juiciosa y conciente. Fue desde su creación el interlocutor, en representación de los mineros, de la Patronal Minera de Asturias quien agrupaba a todas las grandes empresas mineras, salvo Hullera Española.

Los debates sobre el posicionamiento de la revolución rusa y la adhesión a la Internacional Comunista, ocupaban gran parte de las cuestiones internas, tanto en el Sindicato como en el PSOE. La ruptura en el seno del PSOE, tuvo su reflejo en el Sindicato. Los obreros comunistas asturianos estuvieron afiliados desde el principio al SOMA, y en él desarrollaban su actividad sindical, propugnando la unidad con el Sindicato Único de tendencia anarquista. Representaban el ala izquierdista del Sindicato. La difusión de los logros de los obreros en la Unión Soviética les impulsaba a acciones revolucionarias y movilizaciones huelguísticas de los obreros para conseguir sus objetivos. Pero a pesar de sus diferencias estratégicas de acción con los socialistas, eran concientes de su debilidad numérica, por lo que trataban de arrastrar en acciones conjuntas a las demás organizaciones obreras.

2 SUÁREZ, J., El problema social minero en Asturias, Oviedo, 1896: «Creemos firmemente que siempre puede prevenirse una huelga minera de carácter general, si con prudencia y energía se adoptan las convenientes medidas preventivas, para mantenerlas y hacerlas eficaces se cuentan con 300 ó 400 hombres del ejercito", citado por Moradiellos Enrique, El Sindicato de los Obreros Mineros de Asturias, 1910-1930, Oviedo, Universidad de Oviedo, 1986 pág. 37. 
Al principio, el SOMA tuvo una política agresiva, lo que le permitió captar la simpatía de los mineros. De los 1.800 afiliados en 1911, pasó a 28.883 en 1919. A partir de la huelga general revolucionaria de agosto de 1917, que resultó ser un fracaso tanto en Asturias cómo a nivel nacional, el SOMA adoptó una estrategia más conciliadora, colocando a los mineros en condiciones más desfavorable frente a la Patronal ${ }^{3}$. El 4 de septiembre de aquel año emitía una nota en la que hacía constar ${ }^{4}$ :

«1. Que fue a la huelga, como los demás obreros organizados de España, por solidaridad con los ferroviarios del Norte.

2. $\quad$ Que en su deseo de evitar trastornos y quebrantos a la industria minera, trató de reanudar los trabajos de conservación en las minas a los pocos días de comenzar la huelga, no pudiendo realizarlo por causas ajenas a su voluntad y que en su día tendrán la debida explicación.[..]

4. Que esta entidad obrera está animada de rectos propósitos para poner término a una situación que tanto perjudica a la nación entera, siempre que sean respetados los derechos de la clase obrera en general.»

Terminada la guerra mundial, se acabaron los días de bonanzas que permitieron altos beneficios para los propietarios de las minas, sin que se hubiesen mejorado sustancialmente las condiciones de vida de los obreros.

Como consecuencia, el despido de obreros y la disminución de los jornales acarrearían el desencadenamiento de huelgas. EI SOMA tendría la delicada y difícil tarea de canalizar las protestas de los trabajadores, animados por la revolución rusa, en acciones cada vez más tensas para lograr sus aspiraciones.

El Ingeniero de Minas Fernando Villasante analizó, en una serie de artículos ${ }^{5}$, la situación de la minería española, llegando a las conclusiones:

«Fácil hubiera sido evitar tan lamentables efectos, [se trata de la necesidad de bajar los precios del carbón español haciendo incompatible el laboreo de muchas minas pobres] si los mineros hubiesen aprovechado las pasadas favorables circunstancias del mercado para perfeccionar sus explotacio-

3 Maximiliano ARBoleya escribía en De la acción social. El caso de Asturias, pág. 164, "He podido comprobar un curioso contraste: un patrono me hacía de Llaneza el más acabado elogio y a renglón seguido un minero del Sindicato me daba cuenta de la hostilidad y desconfianza crecientes contra el caudillo, hostilidad y desconfianza que de vez en cuando aminoraba algún triunfo, alguna "piltrafa" que de común acuerdo arrojaban a los obreros, los patronos encantados y el caudillo satisfecho", citado por D. Ruiz, El movimiento obrero en Asturias, Gijón, Júcar, 1979, pág. 132.

4 Revista de Industria Minera de Asturias (RIMA) 16 de septiembre de 1917.

5 RIMA, 1 de mayo y 16 de mayo de 1920. 
nes, agrupando los pequeños negocios para orientarlos hacia grandes empresas que pudieran realizar las necesarias economías en los gastos de producción, y procurando el útil aprovechamiento de los carbones de inferior calidad por destilaciones apropiadas para convertirlos en combustibles líquidos, de tan generales aplicaciones hoy en la industria. Medios hubo para estas progresivas soluciones, aplicando los beneficios del Consorcio Carbonero creado por Real decreto de 12 de julio de 1917, así cómo la Ley de protección de nuevas industrias; pero ya que las iniciativas privadas han sido tan deficientes en este sentido, impónese una acción decisiva de gobierno para estimularlas."

Pero la Patronal mantenía una visión puramente mercantil, obsesionada por los beneficios, sin un alcance de futuro, y el Gobierno nunca presentó opciones creadoras que puedan fortalecer a largo plazo la industria española. Su percepción sobre la situación social, quedó reflejada con el artículo que publicó el financiero Luis Olariaga en El Sol ${ }^{6}$ :

«Las épocas de crisis económicas han amortiguado siempre las agitaciones industriales de los periodos de prosperidad. Podrán ser épocas de revolución, pero no de huelgas a granel. Para las huelgas no hay mejor incubadora que una atmósfera de buenos negocios. [.] Estos últimos años los estímulos del proletariado para organizar huelgas han sido mucho más intensos que en otras ocasiones, y las revoluciones rusas, húngara y alemana fueron tremendas excitaciones a la transformación social. [.] No aprendió nada que supusiera idealidad, responsabilidad y sacrificio.»

Imbuida en esta creencia, la Patronal actuó sin consideraciones hacia la clase trabajadora, convencida que ésta no estaba en condiciones de oponerse a sus planteamientos.

En octubre de 1919, el SOMA logró unas de sus mayores conquistas, la jornada de siete horas en el interior de las minas. Este éxito fue debido en gran parte a Llaneza quien, con talante negociador, supo obtener para los mineros mejoras en sus condiciones laborales, aprovechando los buenos resultados económicos obtenidos a lo largo de la guerra.

El 28 de febrero de 1920, el SOMA celebró un Congreso en el cual se aprobó la petición de un aumento salarial del 60 por ciento sobre el salario mínimo de 1913. Por su parte la Patronal sólo accedió a un 30 por ciento de aumento. Las bases sindicales se radicalizaron fuertemente, sin duda bajo la influencia de los comunistas que llevaban campañas de divulgación de los éxitos de la revolución rusa. Así pues, en abril se declaró la huelga

6 Reproducido en RIMA,16 de enero de 1921. 
general que paralizó todas las cuencas mineras, incluso la del Aller donde predominaba el Sindicato Católico. La acción de éste fue una clara demostración de cómo era manipulado por la Patronal para poder controlar el mundo laboral. Con la aceptación por parte del Sindicato Católico de la oferta de Hullera Española de un aumento del 20 por ciento, se puso fin a la huelga el 9 de abril, rompiendo la unidad sindical ?

En las cuencas mineras se respiraba un ambiente tenso y los dirigentes del SOMA se veían desbordados por la radicalización que dominaba entre los afiliados. En Turón, en diciembre de $1920^{8}$, los obreros de la Sociedad Hulleras del Turón arrastraron, con la huelga provocada por el despido de cinco compañeros, al resto de las cuencas a una nueva huelga general ${ }^{9}$. Prácticamente durante todo el mes, los mineros se enfrentaron tanto a la Patronal cómo a la dirección del SOMA quien abogaba por la conclusión del conflicto ${ }^{10}$.

Los comunistas publicaban manifiestos con llamamientos a la UGT y a la CNT para apoyar su propuesta de unidad, constituyendo «Consejos obreros que agrupen al proletariado para la lucha revolucionaria en el momento actual y para la dirección comunista después de la revolución triunfante» ${ }^{11}$.

Para la Patronal, para conseguir la baja del precio del carbón regional, «tienen que acudir los mineros asturianos a la reducción del precio de la mano de obra y a la intensificación de rendimientos; a velar por la fiel observancia de la Ley de Protección a la Producción Nacional de 14 de febrero de 1907; a la protección arancelaria; y al restablecimiento de la exención del impuesto del 3 por 100 sobre el producto bruto del carbón y a la supresión de impuestos restablecidos o creados sobre la producción de combustibles minerales con ocasión de los beneficios extraordinarios del período de la guerra".

\footnotetext{
7 Es interesante leer en El Carbayon del 6 de abril y 8 de abril de 1920 , el desarrollo de las conversaciones y los planteamientos del sindicato católico. Con el título «Grandioso triunfo del Sindicato católico» se explica como fue rebajando sus pretensiones del 40 por ciento al 20 por ciento, terminando el articulo con un ¡Viva el Sindicalismo católico internacional!

\& El Carbayon, del sábado 4 de diciembre de 1920, escribía en el artículo «Empieza la huelga minera», "En las primeras horas de la mañana de ayer comenzó el paro general en las minas de Asturias, excepción hecha de las pertenecientes a la Sociedad Hullera Española en las que los obreros afiliados al sindicato católico minero continúan trabajando.»

a El Socialista. 15 de diciembre de 1920, «La huelga».

10 En el Congreso de Mayo de 1922, Llaneza señalaba que 1920 finalizaba «con una huelga que tuvo para nuestra organización funestisimas consecuencias no sólo por los daños que ella originó, sino porque significó el comienzo del cisma que tantos males causó a la disciplina y a la hermandad de los trabajadores".

11 Archivo Histórico del Partido Comunista de España (AHPCE) «El partido comunista al proletariado español», 11 septiembre 1920, Carpeta 3.
} 
El 25 de marzo de 1921 Llaneza pronunció una conferencia en Mieres ${ }^{12}$ en la que hizo un análisis detallado sobre la crisis industrial minera, y las circunstancias en que se estaba desarrollando:

«Al perder el crédito industrial, pudimos obtener en cambio otras ventajas. Si las enormes ganancias obtenidas por el capitalismo minero se hubiesen invertido en el mejoramiento de los medios de explotación, en el mejoramiento de las condiciones de vida del obrero, del técnico, en el de la extractiva y sus derivadas, cosas de la incumbencia del patrono, que no hizo por su culpa o ignorancia, estaríamos hoy en circunstancias un tanto ventajosas para promover la competencia con el producto extranjero».

En mayo, la Patronal, sintiéndose respaldada por el Gobierno, tomó la decisión unilateral de bajar los jornales, lo que provocó graves tensiones en el Comité Ejecutivo del SOMA.

En el Congreso del SOMA, del 29 de mayo de 1921, con asistencia de 71 secciones representando a 15.607 afiliados, el secretario del SOMA, Manuel Llaneza, opuesto a la huelga, se quedó en minoría y dimitió de la Secretaria junto con los miembros del Comité Ejecutivo.

Pero en el mes de junio logró otra vez tomar las riendas del Sindicato Minero al someter la cuestión a referéndum entre las bases sindicales, logrando 5.332 votos a su favor, 85 en contra y 432 abstenciones ${ }^{13}$. Llaneza desarrolló una gran actividad contra los «terceristas», tratando de evitar que la escisión comunista del Partido Socialista afectara al Sindicato.

El 17 de julio, otra vez por medio de un referéndum entre los mineros, a pesar de que la mayoría de las secciones se declarasen favorables al paro, el Ejecutivo trató de invalidar la votación enfrentándose al clamor generalizado para ir a la huelga.

El 25 de este mismo mes, Llaneza seguía oponiéndose a la huelga manteniéndose la confusión en el Sindicato. No obstante el fantasma de la huelga general recorría el ambiente financiero:

«Según todas las apariencias, no pasara el verano sin que se produzca una huelga general minera en la región asturiana. Tendrá esta huelga, por sus antecedentes y por el momento en que se plantea, una importancia indudable dentro de la lucha entre el capital y el trabajo ${ }^{14}$.»

12 RIMA, 16 de marzo de 1921

13 Álvarez, Ramón, José Maria Martínez. Símbolo ejemplar del Obrerismo Militante, Ed. Autor, Gijón, 1990, pág. 69.

14 RIMA, 16 de agosto de 1921. 
El 5 de agosto de 1921, en el Centro Obrero de Oviedo, se celebró un Congreso extraordinario del SOMA para tratar sobre la postura del Comité, y en particular de Llaneza. El Congreso desaprobó la gestión del Comité por 4.782 votos a favor, ante 2.988 en contra y 462 abstenciones ${ }^{15}$. Por 4.567 votos contra 3.413 y 263 abstenciones, se exigió su dimisión y la de todo el Comité. Llaneza se encontró desautorizado y planteó su dimisión. Fueron elegidos entonces, como presidente: Manuel Díaz, como Vicepresidente: Ovidio Gutiérrez, como Secretario: Enrique García, como Vicesecretario: Félix López, y como tesorero: Eusebio Marcos ${ }^{16}$.

Se aprovechó la nueva situación para proponer la unidad con el Sindicato Único de Mineros, de influencia anarquista, que venía funcionando desde 1919. El 5 de septiembre se celebró una reunión conjunta entre el SOMA y el sindicato único de la CNT, en el centro «La Justicia» de La Felguera, lográndose la fusión de los sindicatos, firmada por José Cosió, Jesús Rodríguez y Baldomero Álvarez del Sindicato único, y José Calleja, Marcelino Magdalena y Hermenegildo Peón del SOMA, disolviéndose el Sindicato único. Los comunistas asturianos alcanzaban así la unidad de todos los mineros, mostrando su empeño en que era posible presentar un frente común a la Patronal.

Es evidente que para Llaneza el nuevo rumbo del Sindicato le preocupaba y no estaba dispuesto a dejarlo actuar sin presentar un frente crítico, defendiendo lo conseguido, destacando, en una conferencia en el Centro Obrero de Mieres ${ }^{17}$, que lo importante para los mineros asturianos era haber logrado la jornada de siete horas en el interior de la mina ${ }^{18}$.

La situación en el Sindicato se deterioraba constantemente. La lucha por el poder entre socialistas y comunistas daba lugar a multitud de mítines en toda la cuenca minera para obtener el apoyo de los mineros. En octubre del mismo año se reúne por tercera vez el Congreso del Sindica-

15 SABORIT, A., Asturias y sus hombres, ob. cit., pág. 185.

16 El Gobierno seguía con atención los acontecimientos en el seno del SOMA. El 19 de agosto de 1921, el Gobernador de Oviedo enviaba el siguiente telegrama al Ministro de Gobernación: "Comité ejecutivo minero, renovado con elemento caracterizadamente sindicalista, según he puesto conocimiento ese Ministerio en telegrama fecha $1 .^{\circ}$ de los corrientes, acordó funcionar con estas agrupaciones de caracter sindicalista de que estaba distanciado, adhiriéndose a la Internacional de Sindicatos Rojos de Moscú. Vengo prestando debida atención nueva orientación por cuanto importa movimiento societario y puede afectar orden publico». AHN, leg. 58, exp. 33.

17 RIMA, 1 de octubre de 1921.

18 «Pero hay una mejora que los mineros españoles hemos conseguido, que no han podido aún alcanzar ningún país del mundo a pesar de sus grandes organizaciones. Esta es la jornada de siete horas en el interior de la mina." En 1927 el propio SOMA mostrara su conformidad a la vuelta a ocho horas en el interior de las minas, lo que le enfrentara directamente al SUM. 
to Minero, con la asistencia de delegados de 64 secciones representando 8.550 afiliados. Por 4.241 votos contra 2.030 y 664 abstenciones, el Ejecutivo provisional comunista es derrotado, saliendo elegido Presidente, Belarmino Tomas, y Secretario General, Manuel Llaneza.

A lo largo de todo el mes se celebraron numerosos actos convocados por las diversas fuerzas de izquierda, enfrentándose comunistas y socialistas sobre las tácticas y los objetivos que se pretendían alcanzar. Las cuencas mineras se veían repletas de mítines de los dirigentes obreros. Si bien los responsables del SOMA recorrían los centros obreros, también desarrollaban una febril actividad los dirigentes comunistas, obligando a los primeros a tomar decisiones para no dejar en manos de estos la iniciativa de las reivindicaciones. Así pues, el 16 de diciembre se declaró la huelga general que sorprendió a todos por la unanimidad y la fuerza con la cual se inició, obligando al Gobierno a acordar «trabajar en las minas de Asturias cinco días por semana, durante las dos próximas, para dar tiempo al estudio de soluciones definitivas de protección a la industria hullera y a un nuevo régimen de trabajo».

EI SOMA, aprovechó la situación para ordenar reanudar el trabajo, pero la Patronal quien había conseguido «medidas de protección», anunció unilateralmente que, a partir del 1 de enero de 1922, las minas asturianas se regirían con nuevas normas que ella misma elaboró.

Los mineros seguían dispuestos a lanzarse a la lucha, y no dudaban en manifestar al Comité Ejecutivo del Sindicato su firme voluntad en impedir que la Patronal decidiera unilateralmente. El día 5 de enero el Comité hizo un llamamiento a los mineros para examinar detenidamente las circunstancias en las cuales se encontraban, indicando claramente que no se estaba en condiciones de ir a la huelga, y convocaba un Congreso extraordinario para el día 8 de este mismo mes en el Centro Obrero de Mieres.

El Congreso despertó una gran expectación, teniendo que permanecer fuera un elevado número de mineros, ya que el local estaba completamente abarrotado. En él los comunistas se enfrentaron verbalmente con los miembros del Comité, creándose un debate muy acalorado, llegando a alcanzar momentos de confusión. Finalmente, se acordó declarar la huelga general ${ }^{19}$ que finalizó el 27 de enero logrando la Patronal que el Gobierno le concediese ventajas fiscales, mientras tanto persistía entre los mineros un mar de fondo que se plasmaba en perturbaciones aisladas que reflejaban el estado de animo de éstos.

$19 \quad$ RIMA, 16 de enero de 1922. 
El 22 de abril, la Patronal mantuvo una reunión con los representantes del SOMA, al término de la cual publicó la siguiente nota ${ }^{20}$ :

«La Asociación Patronal de Mineros Asturianos, ha notificado a la representación del Sindicato de Obreros Mineros, en una reunión celebrada en la tarde de hoy, que no puede vender el carbón por el elevado precio de coste actual y la escasez del rendimiento para competir con otros productos mineros nacionales y extranjeros, viéndose, por tanto, sus asociados, en la dolorosa necesidad de rebajar los salarios de los obreros en un 20 por ciento de su importe total, a partir del 15 de mayo próximo.»

Manuel Llaneza envió entonces a la prensa un escrito criticando la actitud de la Patronal ${ }^{21}$ :

«Nuestros patronos no encuentran más solución, ni más tabla salvadora, que la reducción de los salarios.”

Para la Patronal la situación debía de solucionarse con el sacrificio de los obreros, a quien «les llega una época dolorosa de la lucha por la vida, y ahora mismo están sufriendo las consecuencias de la lucha, a juzgar por el tiempo que ésta dura».

El día 15 de mayo, se reunieron las comisiones de patronos y obreros, manteniendo los primeros su postura de rebajar en un 20 por ciento los salarios.

Se celebró entonces un nuevo Congreso extraordinario en Oviedo el día 19 de mayo. Estaban presente 59 Secciones representando 7.214 afiliados. Tuvo lugar a puertas cerradas para evitar que se «infiltren» no afiliados y se decidió, por 44 secciones contra 15, declarar la huelga general. Los delegados comunistas desplegaron una serie de criticas contra Llaneza tratando de evitar su control sobre la dirección de la huelga, y este se vio entonces en la obligación de intervenir para rechazar la petición de que no abanderase la huelga, atacando duramente la pretensión de los comunistas de aislar al Comité:

«El Comité estima que sería en él una cobardía abandonar en estos momentos este puesto, a pesar de haber tenido una opinión contraria a la manifestada por las Secciones. Por eso se ofrece y os dice que si se quiere que dirijamos el movimiento lo haremos con toda la fe y el entusiasmo posibles, procurando hacer lo necesario para lograr las mayores ventajas para el Sin-

20 RIMA, 1 de mayo de 1922

21 lbidem. 
dicato. Pero en el caso de que no se confíe en nosotros para la dirección de la huelga, tengo que advertir que hay que echarnos, pues nosotros no nos vamos de nuestro puesto, no queremos desertar voluntariamente.»

Los comunistas, unidos a los anarquistas, lanzaron la consigna: «Ni un céntimo menos, ni un minuto más». Los mineros arrastrados por las secciones controladas por los comunistas, y bajo la presidencia de Manuel Díaz, representante de Turón, declararon la huelga, y la dirección del SOMA no tuvo más remedio que sumarse a ella.

El Gobernador Civil propuso el aplazamiento de la huelga hasta el 1 de junio para tratar de gestionar una solución al conflicto en Madrid. El Comité puso como condición la suspensión por parte de la Patronal de rebajar los salarios. Frente a la negativa de ésta, la huelga comenzó el 22 de mayo.

Los comunistas intentaron por todos sus medios controlar la huelga. El 17 de junio se convocó una Asamblea Regional del Frente Único con la presencia de 60 delegados y representación de Secciones de Ujo, Piñeres, Blimea, Lieres y Carborana entre otras, es decir, las Secciones donde los «terceristas» dominaban el Sindicato, para constituir el Frente Único de solidaridad con los huelguistas. Los comunistas con la creación de este Frente Único, bajo la presidencia de Eduardo Castro, pretendían canalizar las ayudas a los huelguistas, y sentar las bases para un embrión sindical que se opusiera al SOMA. La situación que enfrentaba la Dirección del Sindicato a los dirigentes del Frente Único creaba situaciones de excitación radical para atraerse a los trabajadores. Los primeros buscaban lograr lo antes posibles soluciones pactadas, mientras que los segundos se organizaban para un enfrentamiento más directo con la Patronal y el Gobierno.

La represión de la huelga por parte del ejercito acentuó aún más la tensión existente. A las dos compañías del Ejercito trasladadas de Langreo, se unió, el 26 de junio, un escuadrón de caballería procedente de La Coruña.

La huelga se terminó el 9 de agosto, después de ochenta días, aceptándose prácticamente las propuestas de la Asociación Patronal de Mineros Asturianos. Sometido a votación de las bases, el acuerdo fue aprobado por 7.766 votos contra 2.295 y 40 papeletas en blanco ${ }^{22}$. Los mineros mostraban, más que su acuerdo para volver al trabajo, las dificultades de proseguir el conflicto después de casi tres meses de huelga.

22 Saborit, A., ob. cit., pág. 206. Díaz Nosty, B., «Asturias bajo el signo de la Revolución» en Historia de Asturias, Tomo 8, Salinas, Ayalga, 1977, escribe: «por 5.460 votos contra 2.329, se acordó la vuelta al trabajo.», pág. 189. 
La situación en el interior del Sindicato se volvía difícil, con enfrentamientos continuos que impedían al Comité tomar resoluciones. EI SOMA se encontraba frente a una parálisis total de su Comité Ejecutivo. El 25 de junio de 1922, este Comité decidió expulsar las secciones que vulnerasen el reglamento disciplinario. Se trataba de hallar una solución legal que permita terminar de una vez para siempre con la disidencia interna en el Sindicato. Se quedaron fuera 21 secciones ${ }^{23}$.

\section{CONSTITUCIÓN DEL SUM}

Con la expulsión de las secciones del SOMA los comunistas y anarquistas que integraban el Frente Único decidieron disolver la plataforma solidaria y recuperar el Sindicato Único de los Mineros de Asturias.

El 18 de noviembre de 1922, las secciones del SOMA expulsadas se constituyeron en La Felguera, en el Centro Obrero «La Justicia», en Sindicato Único de Mineros de Asturias, adscrito a la CNT, si bien dirigidos por comunistas, e identificado con la ISR. En el Congreso fundacional estaban representados 1.752 afiliados, agrupados en 25 secciones. Avelino González Mallada y Ángel Pestaña intervinieron defendiendo las tesis de la CNT, mientras que Jesús Ibáñez lo hizo en nombre de la ISR, y Máximo Sánchez por el Frente Único ${ }^{24}$.

Las deliberaciones se alargaron hasta la madrugada y prosiguieron el domingo por la mañana aprobándose el informe de la Comisión organizadora y adoptando unos estatutos en la línea de la indicada por la ISR. A la semana siguiente, en Mieres, tuvo lugar la tercera y ultima sesión, confirmando las decisiones, Estatutos y directrices de actuación establecidas en La Felguera, nombrando la Comisión Ejecutiva con residencia en Mieres. El Congreso se clausuró a las seis de la tarde con un mitin.

El Comité Ejecutivo que salió elegido en este Congreso estaba compuesto por Jesús Rodríguez (presidente), José Prieto (vicepresidente),

23 «Hago memoria de que yo aconsejé a Llaneza que no expulsase del Sindicato Minero Asturiano a las secciones mineras influericiadas por el marxismo ruso (leninismo). Estas secciones pueden constituir- le dije- la izquierda de ia organización sindical minera, la oposición, siempre necesaria, dentro de toda organización social o política, con lo que se evitara una escisión del Sindicato, muy peligrosa lo mismo para la integridad y potencialidad de éste que para la causa de las masas mineras y de la democracia. No atendió Llaneza mis indicaciones." A. Oliveros, Asturias en el resurgimiento español, Gijón, Silverio Cañada, 1989, pág. 185.

24 La Antorcha, 1 de diciembre de 1922. 
Benjamín Escobar (Secretario), Críspulo Gutiérrez, vicesecretario, y Jesús Huelga (tesorero) ${ }^{25}$.

Para dar una idea de lo que significó la expulsión de varias secciones del SOMA y la creación del SUM, se puede señalar que los afiliados al SOMA alcanzaban la cifra de 28.883 en $1919,24.551$ en $1920,20.000$ en 1921 y 7.500 en $1922{ }^{26}$. Es decir que entre 1920 y 192217.000 afiliados se dieron de baja del SOMA. Claro esta no todos se fueron al SUM, y como siempre la desilusión se apoderó de los militantes que ignoraron entonces cualquier sindicato.

EI SUM, queriendo ser alternativa a la influencia socialista, emprendió movilizaciones entre los mineros para ampliar las reivindicaciones laborales. Sus actuaciones fueron intensas, participando en las diversas concentraciones de trabajadores, planteando sus puntos de vista y sus criticas a los dirigentes sociales de forma intempestiva y agresiva. Los llamamientos continuos a la unidad no obedecieron sólo, para los dirigentes asturianos, a consignas políticas. Eran concientes de que los problemas de la minería afectaba a toda la población minera por lo cual las acciones debían de ser conjuntas si se pretendía tener éxito.

\section{EL SUM Y EL MOVIMIENTO OBRERO ¿CUÁL FUE SU INFLUENCIA EN LOS MOVIMIENTOS OBREROS?}

La política de la dirección del PCE, con todas las vicisitudes de aquellos años, era la política de la IC quien establecía unos esquemas teóricos sobre la situación, condiciones y estrategias del movimiento obrero minero asturiano. Así pues hay que destacar la falta de sintonía entre esta dirección nacional y los responsables comunistas de Asturias. Estos últimos, si bien eran críticos con la posición de Llaneza, no deseaban la creación de un nuevo sindicato. Para ellos la unidad de los mineros frente a la Patronal era una condición funclamental para lograr que sus reivindicaciones sean atendidas. También creían, y así fue al principio, que conseguirían atraer los mineros hacia un sindicato más proclive a defender posiciones de clase, y con actitudes más revolucionarias.

El SUM logró el apoyo y el respecto de los mineros asturianos, y el SOMA vio peligrar su influencia entre estos últimos. A partir de su creación

\footnotetext{
25 El Noroeste, 21 y 29 de noviembre de 1922.

26 SHUBERT, A., ob. cit.
} 
llevó una campaña de atracción de los mineros, al mismo tiempo que trataba de descalificar al SOMA, y en particular a su secretario Llaneza:

"Los compañeros del SUM han emprendido una serie de mítines para atraer al Sindicato el resto de los Asturianos. Con este fin han publicado un manifiesto en el que una vez más desenmascaran los manejos caciquiles de Llaneza y comparsa» 27.

EI SUM nacía con la bandera de la revolución y con miras hacia los soviets. Sus militantes, tanto comunistas como anarquistas, cobijaban las mismas aspiraciones y todas sus acciones se desarrollaron bajo el signo de la lucha de clases. Siguió afiliado a la CNT, participando en las actividades de la Confederación Regional de Asturias, León y Palencia hasta 1931. A partir de entonces, se quedó adherido a la ISR y a la CGTU quien era la que representaba la ISR en España.

Pero los problemas orgánicos que existían en el seno del PCE tenían que manifestarse por obligación en el SUM. Las relaciones entre la fuerza política y la fuerza sindical estaban impregnadas de desconexión entre los dirigentes y la clase social.

En las constantes movilizaciones los militantes del SUM participaban de forma activa en la defensa de sus reivindicaciones lo que atraía los mineros hacia el SUM. Existió desde el principio una competencia entre el SUM y la SOMA para conquistar los mineros, y una lucha, algunas veces violenta, para demostrar su condición de sindicato de clase, ya que los dos se disputaban el mismo terreno. La lucha sindical estaba, por supuesto, directamente ligada a las políticas del PSOE y el PCE, y como telón de fondo estaba la IC que intervenía en la definición de las tácticas a desarrollar para la conquista del poder.

La colaboración de los socialistas, "por oportunismo táctico», con la dictadura ${ }^{28}$, dejó en manos del SUM el protagonismo de las reivindicaciones de los mineros, lo que motivó fuertes enfrentamientos entre éste y el SOMA. En los primeros momentos de la dictadura del general Primo de

27 La Antorcha, 26 de enero de 1923.

28 El 24 de marzo de 1925, el Subsecretario de Gobernación enviaba a los Gobernadores Cjviles la circular n. ${ }^{\circ} 128$, en la que decía: «Por encargo del Sr. Presidente del Directorio encarezco a VS que sin prejuicio de velar en todo momento porque se cumplan las disposiciones vigentes en materia de voto corporativo, no se creen dificultades a las corporaciones o asociaciones de carácter socialista, teniendo en cuenta que la política del Directorio no ha sido en ningún modo la de perserguirles o impedir su funcionamiento y el ejercicio de sus derechos y que no se avendría con esa política el crear un ambiente de descontento en las fuerzas socialistas por cuestiones que deben desenvolverse con arreglo a normas de justicia." AHN, leg. 58, exp. 34. 
Rivera, ni los comunistas, ni el SUM, sufrieron persecución. Las autoridades minimizaban su influencia y no quisieron enfrentarse a las organizaciones obreras. Esperaron hasta diciembre de 1923 para "descubrir" un supuesto complot revolucionario con ramificaciones en Portugal y en Asturias, para realizar detenciones y suspender las actividades del SUM.

En esta situación el SUM encontró dificultades para su acción lo que frenó su implantación entre los mineros. El desahucio de los locales de las sociedades obreras obligaba a los militantes del SUM a utilizar los chigres como lugar de encuentro. La posición del PCE que querría imponer su política en el SUM fue motivo, a su vez, de debilitamiento del sindicato.

Las reivindicaciones eran de diversa índole, desde peticiones sobre salubridad en las minas, hasta salarios mas adecuados a la carestía de vida, pasando por condiciones de vida dignas, con viviendas higiénicas, centros culturales y escuelas para los hijos, así como también apoyo solidario a compañeros de otras minas. Los conflictos adquirían cada vez más una componente política que caracterizaría los movimientos obreros, destacando entonces el poder de convocatoria y de implantación de los comunistas y anarquistas. Ya en marzo de 1930, con las elecciones de la representación obrera para la dirección del Orfanato, se había podido comprobar el peso que significaban, entre los trabajadores, los candidatos comunistas Prieto Martínez e Iglesias Cuevas al lograr en Mieres mayor número de votos que Amador Fernández y Belarmino Tomas, siendo superados únicamente por Llaneza, y venciendo holgadamente en Turón.

En mayo de 1930, el SUM fue autorizado a reabrir locales y a actuar legalmente, y el ultimo domingo del mes, se reunió en el teatro «Novedades» de Mieres el Congreso del SUM.

En noviembre de 1930, a raíz de unas huelgas en Hullera de Riosa, el SUM hizo un llamamiento a la solidaridad para extender el movimiento huelguístico. La reacción del SOMA, contrario a la huelga, fue de ataque directo al SUM por apoyar la huelga acusándola de «carnavalada ${ }^{29}$ ».

La huelga minera de junio de 1931 enfrentó claramente las tendencias comunistas y cenetistas que componían el sindicato. Este enfrentamiento culminó en la ruptura con la CNT, y tuvo como consecuencia el debilitamiento del SUM. Su fuerza principal estaba localizada mayoritariamente en Aller, Sama, Turón, Pola de Lena, Sotrondio y Carbayín. Pero su fuerza más destacada estaba en Turón de donde eran sus principales dirigen-

29. La Aurora social, 21 de noviembre de 1931: «La última "huelga general"». Nota Oficiosa del Sindicato de Obreros Mineros de Asturias». 
tes. EI SUM planteó reivindicaciones pidiendo unas revisiones de las bases salariales y de la jornada impuesta durante la dictadura. El gobierno propuso esperar hasta que las Constituyentes definieran el precio del carbón. El SOMA, dirigido entonces por Amador Fernández, mostró su acuerdo sobre esta propuesta, pero los comunistas y los anarcosindicalistas del SUM pedían al gobierno un gesto derogando el horario impuesto en la anterior legislatura. EI SOMA definió su táctica atacando al SUM y poniendo todos sus medios para sabotear la huelga. Se trataba de una actitud de fuerza entre los dos sindicatos ${ }^{30}$. Ésta era la situación cuando tuvo lugar el Congreso Nacional de la CNT celebrado en el Conservatorio de Madrid. Como representantes del SUM asistieron Benjamín Escobar, vicesecretario del sindicato, y Ceferino A. Rey quien sería el secretario general en 1932. Ambos pertenecían al PCE. En su intervención pidieron al Congreso que les prestasen más ayuda en la huelga que estaban llevando a cabo en aquellos días. Pero la CNT, que apoyaba el Pacto de San Sebastián, se negó a intervenir directamente, y propuso nombrar una delegación para pedir el arbitraje del Gobierno ${ }^{31}$.

EI CE del PCE parecía totalmente alejado del grave problema que estaba teniendo lugar en Asturias. Ni en la reunión de junio de 1931, ni en la del 16 de agosto el asunto mereció un análisis serio con resoluciones apropiadas. En esta ultima reunión del Secretariado Sindical del CE del PCE ${ }^{32}$ se habló de un Congreso de unidad, insistiendo en la necesidad de crear las fracciones sindicales comunistas y las minorías de oposición, pero sin mencionar cualquier análisis de problemas sindicales concretos como los que se habían tenido en Asturias el mes pasado.

En 1932 el Comité Provisional de la CGTU emitió una nota titulada «Resoluciones sobre las tareas del Sindicato Único de Obreros Mineros de Asturias» ${ }^{33}$ en la que destaca que «el Sindicato Único de Obreros Mineros de Asturias atraviesa un periodo de estancamiento impropio de la influen-

30 El Sol, Madrid, 31/5/1931, «El Sindicato Único persiste en ir a la huelga en las minas».

31 Hay que notar como el SUM se dirigió a la CNT y no al CNR de la CNT para pedir apoyo a la huelga. En el acta de la reunión del 6 de junio de 1931 del Comité Ejecutivo del PCE, para discutir sobre la cuestión sindical, AHPCE, microfilme IV(60), se discutió ampliamente sobre el próximo congreso de la CNT, y sólo al final se abordó el problema de la huelga que sostenía el SUM, decidiendo dar por parte del CNR un donativo de 1.000 ptas., y que «en el primer número de Mundo Obrero, se inserte el llamamiento del CNR invitando a los obreros a solidarizarse con los mineros». Pero sin emitir una sola orientación al conflicto.

32 AHPCE, «Nuestras tareas inmediatas en el dominio sindical», 16 de agosto de 1931, Microfilme IV (64).

${ }_{33}$ AHPCE, caja 135, carp. 2, «Resolución sobre las tareas inmediatas del Sindicato Único de Obreros Mineros de Asturias», 1 de agosto de 1932. 
cia cada día mayor de que goza entre las grandes masas», atacando «los dirigentes socialfascistas del SOMA», y en un afán de voluntarismo enfatiza que "solo el SUM goza de la simpatía y del apoyo general de las masas en toda la zona minera y su influencia aumenta sin interrupción».

Por primera vez se aclaraba un modelo organizativo, reconociendo que «las antiguas secciones en los lugares de vivienda no responden a las nuevas modalidades de las luchas, pues están calcadas según la estructura del viejo Sindicato Minero", y proponiendo «trasladar las secciones a los lugares mismos del trabajo, a las bocaminas, y proceder a las reuniones de las secciones de tal forma que puedan participar en ellas el mayor numero de obreros aunque no estén sindicados».

La organización del Comité Sindical se estructuraba «en forma de Secretariado formado por seis secretarios: el de organización, agitación y propaganda, administrativo, juvenil, seguridad e higiene, y femenino". Los integrantes del Secretariado debían ser de la misma localidad para facilitar las reuniones que debían ser de dos veces por semana. Cada mes debía celebrarse un Pleno formado por el Secretariado más un delegado de cada Comarcal.

Estaba previsto que por lo menos un cargo, el secretario de organización ó el de agitación y propaganda, sean retribuidos, lo que permitiría efectuar "con rapidez la confección y el envío de circulares, manifiestos, cartas, etc.».

A partir de mayo de 1930, disponía de 30 secciones con unos 6 ó 7.000 afiliados. A principios de 1931, el SUM afirmaba tener 42 secciones y unos 9.000 asociados, alcanzando las cifras de 54 secciones y 10.000 asociados en agosto de $1932{ }^{34}$. Por su parte, D. Ángel García Otermin, auditor General de Oviedo, indicaba que en 1932 el SOMA contaba con 13.346 afiliados, de los cuales menos de 10.000 eran cotizantes, y el SUM con 6.046 cotizantes, aunque subrayaba que este último era «una entidad paupérrima, que para los efectos de organizar, entiéndase bien, de organizar la revolución, no contaba ${ }^{35}$.» Por otra parte, en la Conferencia Nacional de Unidad Sindical de 1932, se indicaba que estaban representados 5.724 afiliados al SUM.

\footnotetext{
34 Ver Samuel RodRíguez, “Implantación y confrontación en el sindicalismo de clase, 19311934.» en Estudio de Historia social, n. ${ }^{\circ} 31,1984$, pág. 105.

35 Informe del Auditor General de Oviedo, don Ángel García Otermin, al Ministro de la Guerra, en Sánchez, J.A. y SAuCo, G., La revolución de 1934 en Asturias, Madrid, Ed. Nacional, 1974, págs. 274-284.
} 
Después de la crisis de 1931, el SUM se mantuvo en una línea descendente, y recibía las criticas de la CGTU, que no se explicaba como no lograba arrebatarle el liderazgo al SOMA, pero sin esbozar ni un análisis, ni ayuda política para salir del atolladero de la situación.

«El Sindicato Único de Obreros Mineros de Asturias atraviesa un periodo de estancamiento impropio de la influencia cada día mayor de que goza entre las grandes masas: Esta crisis de crecimiento solo puede explicarse por la falta de una dirección eficaz y coordinada que convierta el Sindicato en el órgano verdaderamente dirigente de todas las luchas del proletariado minero" ${ }^{36}$.

Se puede adelantar que hasta la escisión anarquista de finales de 1931, el SUM mantenía una afiliación del mismo orden que el SOMA el cual había sufrido un gran bajón en el año 1928, recuperándose en los años siguientes. A partir de 1931 se redujo considerablemente el número de militantes del SUM por la salida de militantes anarquistas y seguramente por su paso al SOMA ${ }^{37}$.

Parece curioso observar como mientras la afiliación al SUM sufre una caída a partir de 1931, los afiliados al PCE en Asturias aumentan notablemente. Por otra parte se puede estimar que no más del $10 \%$ de los afiliados al SUM eran militantes comunistas.

\section{EL SUM Y LAS RELACIONES CON EL PCE}

En su primer Congreso, en $1927^{38}$, el PCE proclamaba:

«Declaramos abiertamente que nuestra máxima preocupación esta en los sindicatos, a los cuales queremos llevar nuestro espíritu revolucionario para apartarles del colaboracionismo que corroe a muchos de ellos y entorpece los movimientos del conjunto. Son los sindicatos, en ligazón estrecha de afinidad espiritual con nuestro partido, los que han de derrumbar el edificio capitalista y los que han de regir después las funciones de la producción. Indispensable es, por tanto, que con ellos colaboremos y nos pongamos a la cabeza de sus luchas, desarrollando una acción conjunta que dé la sensación de nuestros propósitos inmediatos y finales.

\footnotetext{
36 AHPCE, caja 135, carp. 2.
}

37 En términos generales se puede esbozar los siguientes datos: 1920: 39.093 mineros, 24.551 militantes del SOMA, 62,8\% mineros pertenecen al sindicato; 1932: 30.420 mineros, 13.000 pertenecen al SOMA, 6.000 al SUM (ISR), y 1.200 al SUM (CNT), lo que suma 20.200 afiliados a sindicatos, es decir, el $66 \%$ de los mineros. Lo que demuestra que no decae, al contrario, el interés de los mineros hacia los sindicatos.

38 La Antorcha, 27 de marzo de 1927. 
Los comunistas que pertenecen a la CNT deben procurar su ingreso definitivo en la ISR y los que pertenecen a la UGT deben influir intensamente con sus Sindicatos para que en el próximo Congreso de ese Organismo se acuerde romper toda clase de relaciones con la Internacional de Ámsterdam, nido de cucos y traidores, e incorporarles a la Internacional Sindical que está apoyando a una República obrera triunfante y empuja sus huestes por las vías revolucionarias."

Esta estrategia fue cambiando a lo largo de los años, y estos cambios motivaron desorientaciones a nivel regional de las organizaciones obreras, creando enfrentamientos con las demás fuerzas sindicales.

Además, la oposición de la Federación Comunista Asturiana (FCA) a la integración de los sindicatos comunistas en el Comité Nacional de Reconstrucción (CNR) de la CNT creaba una tensión en las relaciones entre la dirección del PCE y la FCA ${ }^{39}$, y demuestra claramente que no existía una dependencia ciega al Comité Ejecutivo del PCE. Así, el 20 de diciembre de 1930, el comité Ejecutivo del PCE escribía al Comité Regional de la Federación Asturiana ${ }^{40}$ :

«... Por los informes que tenemos y por lo que se desprende de vuestra carta, el SUM no esta completamente bajo nuestra influencia y dirección, sino que existen reminiscencias anarquistas y bastante confusionismo. Para nosotros no se plantea solo el problema de tener los cargos directivos en el Sindicato, sino que el nervio de la cuestión está en aplicar nuestra política. La confusión se manifiesta en el hecho que el SUM esta adherido a la ISR y no ha tomado acuerdo sobre la cuestión de la Conferencia de Sevilla (es seguro que ni siquiera se planteó la cuestión), ni se ha adherido al CN de Reconstrucción de la CNT, reconociendo en cambio la CNT dirigida por los anarquistas y Berenguer. ¿Cómo explicar esta contradicción? La Conferencia de Sevilla trazó un programa de lucha de acuerdo con la política de la ISR, frente al confusionismo de Pestaña y comparsa, dio su adhesión a la ISR, a

39 Ver carta del 2 de septiembre de 1929 del CE al CR en la que se escribe, entre otras: « hasta la fecha la mayoría de los comunistas de nuestro Partido, son comunistas honorarios, que ni pagan sus cuotas al Partido, y hay que terminar radical y rápidamente con esto. De lo contrario, jamás podremos hacer nada. Las Federaciones deben bastarse a sí mismas para sus gastos. Naturalmente que, dado el estado de desorganización de vuestra Federación, lo demuestra el hecho de que no podáis celebrar un pleno por vuestros propios medios como lo hacen otras Federaciones...», a lo que contestaba el día 7 el Comité Regional: «En cuanto a organización, no negamos lo que podemos llamar abulia de los militantes: pero, de eso a suponer que seamos modelo de desorganización hay un abismo. Se puede asegurar que será este regional el único en España que cobra de una manera normal sus cuotas a los afiliados...». El 20 de octubre de 1929, el CE del PCE escribía a la FCA: «Hemos recibido vuestra carta del 14, en la que. Por no perder vuestra costumbre, y en un tono verdaderamente inacostumbrado e inadmisible en nuestros Partidos, no hacéis otra cosa que censurar al CE», AHPCE, Film II, 39.

40 AHPCE, Film IV, 52. 
la Internacional revolucionaria y nombró un Comité N. de R. para reorganizar la CNT sobre nuevas bases."

Las divergencias entre el Comité ejecutivo del PCE y el Comité Regional de la Federación Asturiana fueron muy tirantes, viendo la Regional "censurada su conducta" por el CE. Las diferencias entre el SUM y la FCA por una parte y el Comité Ejecutivo por otra parte esta claramente reflejada en la correspondencia intercambiada. En ella, este último reprochaba con cierta dureza a la FCA de estar "contra la política Sindical del Partido" ${ }^{41}$, y se insistía reiteradamente al SUM de dejar la CNT y de adherirse al CNR.

"¿Por qué no decís claramente lo que pensáis sobre el CNR? Vosotros aceptáis en el Sindicato Único Minero la representación de la CNT de Pestaña y Berenguer, pero no queréis oír hablar de la Central Sindical afecta a la Internacional Sindical Roja (sección española de la ISR) y, cuando el CE del P. os plantea claramente esta cuestión, calláis.»

\section{LA ESCISIÓN ANARQUISTA}

El 3 de mayo de 1931, se celebró un Congreso del SUM para discutir, entre otros asuntos, sobre su permanencia en la CNT. En medio de acalorados debates, se acordó continuar, y se pidió la celebración de un Congreso extraordinario con la presencia paritaria de la CNT y el Comité Nacional de Reconstrucción. Fue el principio de escisión del SUM.

El 17 de mayo se reunió el primer pleno regional de la CNT de Asturias, al cual asistieron en representacion del Sindicato Único de Obreros Mineros de Asturias José Prieto y Marcelino Iglesias.

El 5 de julio de 1931 se celebró un Congreso extraordinario del SUM para analizar las posiciones del Comité Sindical y de la Regional. Este Congreso sólo sirvió para lanzar acusaciones mutuas, tratando de monopolizar la palabra sin concesiones para el adversario. En estas Asambleas no se pretendía llegar a ningún acuerdo, solo se deseaba echar al adversario, con provocaciones, insultos ó expulsiones. La tensión era demasiado grande para alcanzar cualquier compromiso. A la hora de votar, se aprobó la gestión del Comité Sindical, pero se condenó la actitud de la Regional por 19 Secciones en contra 9 a favor, y 7 abstenciones. Se volvió a plantear la cuestión de la permanencia en la CNT, y se acordó se-

41 AHPCE, microfilm IV(64), cartas del 13 y 14 de febrero de 1931. 
guir, pero imponiendo unas condiciones que equivalían a una auto expulsión. Se alcanzaba así las pretensiones del Ejecutivo del PCE, de monopolizar la orientación del SUM de acuerdo con la táctica del SIR.

El 18 de julio de 1931, el Comité Regional publica una nota ${ }^{42}$ en la que arremete duramente contra el PCE. En ella se escribía:

«Para el Partido Comunista, exclusivista y dogmático, son enemigos del proletariado todos aquellos que no se someten a los mandatos indiscutibles, infalibles, que vienen de Moscú. [..] Al no poder conquistar la CNT, había que dividirla. $Y$ por un motivo de fácil solución, por una de tantas diferencias que surgen y se resuelven normalmente dentro de la organización, se intentó la escisión y fue creada la denominada Confederación Nacional del Trabajo «Revolucionaria» conocida por el mote de "Comité de Reconstrucción de Sevilla», que surgió al conjuro moscovita.»

El domingo 13 de septiembre se celebró un Pleno Regional de la Confederación Regional del Trabajo de Asturias, León y Palencia, en la Felguera, en el Centro Obrero "La Justicia». La mesa del Pleno estaba compuesta por Juan Díaz, del Sindicato Único de Infiesto, Presidente; Avelino Entrialgo, del Sindicato Metalúrgico de Gijón, Secretario de Actas; y Jerónimo Riera, del Sindicato Metalúrgico de La Felguera, Secretario de notas.

Segundo Blanco, Secretario del Comité Regional, empezó la exposición sobre la actuación del Comité Regional en la cuestión minera haciendo historia de los distintos Congresos del SUM, en los cuales, según él, la CNT «y de manera especial el Comité Regional fueron siempre maltratados, insultados, acusados y condenados sin defensa posible». Criticó con especial dureza el hecho que la huelga de junio estuviese teledirigida y orientada por el PCE y el Comité de Reconstrucción de la CNT. A este respecto, señaló que, pese al compromiso del Comité Sindical, tres días antes del Congreso Extraordinario de la CNT, de someter la huelga a referéndum, no lo llevó a cabo ya que se recibió a Oviedo la visita de Roldan, representante de la Sindical Roja, «quien les obligó a no hacerlo, Ilevando el conflicto a limites de desesperación que iba perfilando la diaria tragedia». Avelino Mallado, quien prosiguió la información de Blanco, acabó diciendo que «el criterio del Comité Regional es que se admita al SUM sin necesidad de que se altere su reglamento, pero sujetándose, como todos, a las normas de la CNT, y destituyendo de los cargos representativos a los que figuran como candidatos a concejales ó diputados». Benjamín Escobar, en nombre del SUM, rechazó las imputaciones, ase-

42 Solidaridad, Gijón, 18 de julio de 1931 
gurando que el Sindicato nunca estuvo orientado ó dirigido por los de «Reconstrucción», ni obedeció ordenes de ningún partido, y que estaba de acuerdo en aceptar la disciplina de la organización Confederal, pero que solo las secciones podrían decidir la destitución de los candidatos a cargos políticos.

Para contrarrestar las resoluciones del Pleno Regional de la CNT, el SUM organizó en el cine "Novedades" de Mieres, el 11 de octubre, un Congreso. Se envió a las diferentes secciones el Orden del día, reiterándoles que acudan para oponerse a las resoluciones que habían acordado los anarquistas. El Comité Regional, aunque no fue convocado, acudió al Congreso.

Las deliberaciones fueron de alta tensión, enfrentándose las dos tendencias, comunistas y anarcosindicalistas, para hacer valer su opción.

"Cuando hizo su aparición en la sala la delegación de la CNT fue acogida con muestras de manifiesta hostilidad por los "guardias rojos" que vigilaban el normal desarroflo del Congreso. Uno de los componentes del Comité Sindical Minero, tuvo la osadía de proclamar: "Estamos rodeados de enemigos de abajo, de arriba y del medio. Ceferino Rey, otro destacado militante de la Tercera Sindical Roja, ante la presencia en la sala del Comité Regional cenetista, recordó a los congresistas que el Congreso anterior había acordado abandonar la CNT, y que su representación nada tenia que hacer en las deliberaciones. Arreció el vocerío entre partidarios de que la CNT permaneciera y los que luchaban por excluirla» ${ }^{43}$.

El ambiente se volvió tenso con palabras altisonantes, con voces de «fuera la Regional». De pronto se dio lectura a una carta firmada por 62 personas de la Sección de La Felguera recomendando el ingreso en la ISR, criticando la CNT, y pidiendo al Congreso que retirase la representación oficial de La Felguera. El alboroto era general, y la Confederación Regional decidió retirarse.

Este Congreso se planteaba decisivo para definir como se quedaría el SUM, si los comunistas, como pretendía el Comité Ejecutivo del PCE, se afianzarían en la dirección y aplicarían las órdenes de la Komintern, ó si permanecerían en la CNT, apartándose de las consignas de la ISR. Finalmente prevaleció la postura favorable a la IC. Los comunistas se quedaron con las riendas del SUM, pero habrá que esperar hasta 1932 para que se adhiriese a la ISR.

\footnotetext{
43 Solidaridad, 17 de octubre de 1931.
} 
El 18 de octubre de 1931, se reunieron en la Casa del Pueblo de Gijón, las secciones mineras de Lada, La Felguera, La Nueva, Santa Ana y Carbayin, representaciones de Mieres, Sama, Tras el Canto, Blimea, Turón, y La Tejera, así como la Federación Local de La Felguera y el Comité Regional de Asturias, León y Palencia.

«Tras la lectura de una comunicación de la Local feiguerina conteniendo observaciones sobre el modo de reorganizar las fuerzas sindicales mineras, una vez superada la escisión provocada por los elementos comunistas, el compañero Eladio Fanjul, enviado directo de La Felguera, sugiere la necesidad de crear un Comité provisional de Relaciones que emprenda los trabajos preliminares para la celebración de un Congreso; para evitar los peligros de centralismo autoritario, el Comité Provisional estudiara detenidamente la forma de constituir el definitivo a la luz de lo sucedido.

[..] Concluye la reunión con la decisión de que el Comité Provisional resida en Sama de Langreo, designando a los compañeros Augusto García, Presidente; Faustino Rodríguez, Vicepresidente; Anselmo Nicieza, Secretario; José García, Tesorero; Vocales: por Mieres, Arturo Caldrecha; por Turón, Antonio Rodríguez; por San Andrés, Jesús Fernández; por Carbayin, J. Villa; por Sotrondio, A. Fernández; por La Tejera, A. Rodríguez; y por Santa Ana, S. Álvarez» ${ }^{44}$.

Después de la escisión, la polémica siguió a través de los periódicos Solidaridad, anarquista, y Obrero Astur, órgano de la FCA, y en actos públicos donde cada bando acusaba al otro de traidor.

\section{EL SUM Y LOS CONFLICTOS SOCIALES}

La aplicación de los conceptos estratégicos del SUM se plasmó en una participación concreta en conflictos laborales que se traducían en huelgas, y su número representa un índice de situación frente al número de huelguistas que configura un índice de repercusión.

En el grafico adjunto se puede apreciar como en los años de la dictadura el número de huelgas y de huelguistas se mantuvo reducido, para aumentar a partir de 1930 multiplicándose por 10 el número de huelguistas, mientras que el de las huelgas se cuadriplicó. Fue a partir de aquel año cuando el SUM pudo actuar libremente después de haber visto prohibida su actividad. En las huelgas de 1927, promovidas por el SUM, más de 7.000 mineros secundaron las 25 huelgas que se declararon. El año 1931

44 Solidaridad, 17 de octubre de 1931. 


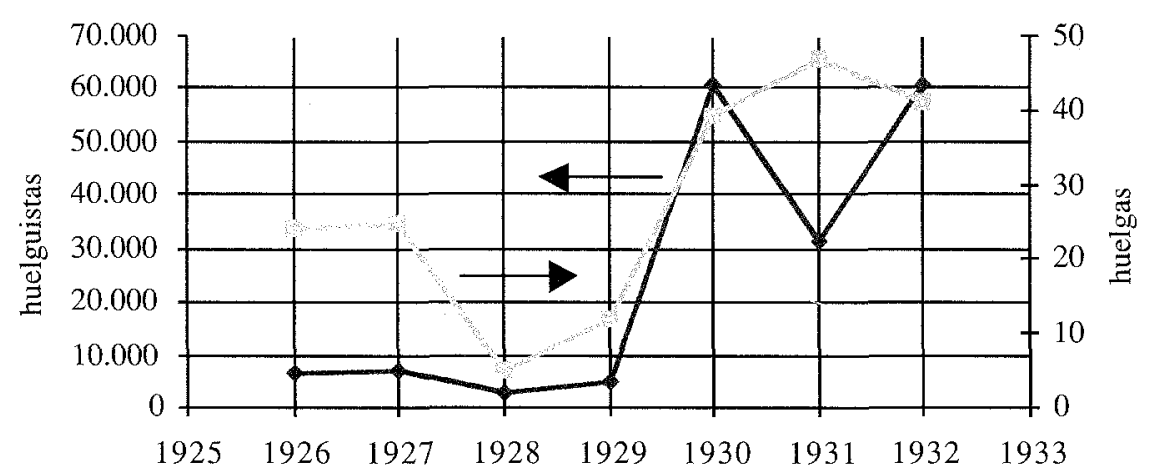

vio el mayor número de huelgas, pero con un seguimiento numérico de huelguista reducido; en aquel año el SOMA no participaba activamente en los movimientos sociales dejando solo al SUM. Cuando en 1932 la participación de los trabajadores se hace conjuntamente SUM y SOMA el número de huelguistas alcanza los $60.000^{45}$.

\section{LA UNIFICACIÓN SINDICAL ¿POR QUÉ EL SUM NO CONSIGUIÓ UNA IMPLANTACIÓN MÁS SOSTENIDA?}

La división del movimiento obrero le incapacitaba para presentar un frente sólido que pueda contrarrestar las fuerzas fascistas que se organizaban en Europa y en España. La insurrección socialista de Austria, aplastada por los fascistas en febrero de 1934, y la tentativa de las Ligas fascistas en Francia de derrocar la Tercera República, eran demostraciones palpables de los derroteros por los cuales se deslizaba Europa. Era imprescindible la unión de todas las organizaciones políticas y sindicales obreras si se quería alcanzar una verdadera oposición. Pero se plantea-

45 Revista Minera Metalúrgica y de ingeniería, $n .{ }^{\circ} 3430,1$ de noviembre de 1934 . Según $\mathrm{B}$. Díaz Nosty, La Comuna Asturiana. Revolución de octubre de 1934, Madrid, Zero,1974, pág. 116, para el año 1932 el total de huelgas declaradas fue de 94 , lo que representaba el 13,87 por ciento sobre el total nacional, afectó a 71.832 obreros de los cuales 59.236 fueron huelguistas, es decir, el $82 \%$, y el promedio de huelguista por huelga fue de 630 . Para el año 1933, estos mismos datos fueron: 95 huelgas, $8,43 \%, 155.136$ obreros afectados, y 105.286 huelguistas, es decir, el $69 \%$, con un promedio de 1.108 huelguista por huelga. 
ban muchos interrogantes en la forma y el fondo de lograrla. Para los comunistas se trataba de ir hacia un frente único, los anarquistas consideraban que la unidad obrera debía contemplar exclusivamente los sindicatos independientemente de los partidos políticos, los socialistas y ugetistas miraban con recelos las demás fuerzas obreras y creían que podrían arrastrar a las fuerzas burguesas republicanas hacia su campo de acción. La unidad si bien siempre era admitida cómo necesaria, también era cierto que provocaba temores entre quienes debían de unirse, con divergencias en los procedimientos y los métodos de funcionamiento para conseguirla.

El 1. ${ }^{\circ}$ de enero de 1922, la IC había lanzado la consigna del Frente Único de la clase trabajadora, y el PCE, se manifestó promoviendo en todas sus organizaciones la creación del Frente Único de las fuerzas de izquierda. Con el Frente Único el PCE pretendió aglutinar y controlar las acciones de los obreros. La organización preconizada para la lucha por reivindicaciones como el aumento de los salarios, la jornada de siete horas, el subsidio de paro ó los derechos sindicales, consistía en el Frente Único mediante la creación de Comités de Fabrica que impulsen las acciones de los trabajadores.

«No hay ningún obrero, por poco consciente que sea, que no comprenda la necesidad de formar un solo frente con los compañeros que trabajan con él en la misma íabrica, en el mismo taller, en la misma mina. El comité de fabrica, elegido por todos los trabajadores de una misma casa sin excepción, estén o no organizados sindicalmente, pertenezcan a la CNT o a la UGT, sea cual sea su filiación política, la ofrece la posibilidad efectiva de establecer esta unidad de acción» ${ }^{46}$.

La táctica del Frente Único por la base, elaborada por la IC, constituyó la baza fundamental del PCE, y representó a lo largo de los años treinta el leit motiv de los comunistas para llevar adelante su política de unidad sindical. En todos sus documentos se hará referencia a él.

El Frente Único no es una especie de termino medio entre la táctica revolucionaria y la reformista (socialista o anarquista) sino la unificación de los trabajadores deseosos de luchar contra los patronos ${ }^{47}$.

46 NiN Andrés, «La situación política, el peligro fascista y la necesidad del Frente Único del proletariado", agosto de 1931, en Los problemas de la revolución española, París, Ruedo Ibérico, 1978, pág. 92.

47 AHPCE, Caja 135, carpeta 13, «Plataforma de lucha para la realización de la unidad sindical de lucha de clase», 1932, pág. 46. 
Para los comunistas el Frente Único era el instrumento primordial para el proletariado, para oponerse a los intentos de involución contrarrevolucionaria y lograr la revolución de los obreros y campesinos a semejanza de Rusia. Toda organización que promoviese agitación social era un eslabón mas hacia el Frente Único.

«Los Comités a base de frente único efectuado en los lugares de trabajo, la creación de los piquetes de milicias obreras y campesinas y la constitución de los Soviets son hoy nuestra tarea central» ${ }^{48}$.

En marzo de 1925, el SOMA celebró su Congreso ${ }^{49}$, y en él se dio lectura a «un extenso documento del Sindicato Único de Mineros, en el que piden la fusión, y sin discusión se acuerda rechazar el escrito y hacer publico que el Sindicato Minero tiene abiertas sus puertas para todos aquellos que lo deseen, no haciéndolo así con los que por su conducta deben ser eliminados de nuestra organización. Por tanto, pueden venir individualmente cuantos lo deseen».

Con la creación del Comité Nacional de Reconstrucción de la CNT se pretendió reactivar el sindicato anarquista que si bien tenia dificultades no estaba moribunda como se demostró. La idea de «reconstruir»la CNT, partió del Comité Ejecutivo de la ISR ${ }^{50}$, quien substituyó la consigna de "unidad a toda costa" de los años 1924-1928, por la de "escisión por doquier». Mas tarde, cambiando de táctica se fomentó la aparición del Comité Nacional de Unión Sindical. Los virajes eran más formales que efectivos ${ }^{51}$, y se asistía a una política de escisión entremezclada con una campaña de unidad, lo que creaba tal confusión que dificultaba a las organizaciones de base atraer las masas revolucionarias de la CNT.

En 1930, se había ordenado desde Paris a la Federación del Transporte de Sevilla preparar una Conferencia para convocar un Congreso $\mathrm{Na}$ cional de Reconstrucción de la CNT. El CNR de la CNT fue creado el 23 de junio de 1930, aunque no tuvo un seguimiento total por parte de los sindicatos comunistas. Los anarquistas denunciaban constantemente esta intromisión:

48 Frente Rojo, 7 de julio de 1932, "El frente único en acción» de Manuel Adame.

49 El Socialista, 16 de marzo de 1925. "Importantes acuerdos del Congreso Minero asturiano".

50 Nin corrobora esta afirmación señalando que pudo « ver y leer, firmada por el secretario general, Lozovsky» la carta oficial que la ISR transmitió al PCE. Los problemas de la revolución española, Paris, Ruedo Ibérico, 1978, pág. 99.

51 Nin Andrés, "La carta abierta de la Internacional Comunista y el Congreso del Partido. La revolución española, el Partido Comunista y la Oposición", Comunismo, marzo de 1932, en Los problemas de la revolución española, París, Ruedo Ibérico, 1978. 
«La Confederación Nacional del Trabajo no puede tolerar que una determinada tendencia (política en este caso) conspire tan innoble y canallescamente contra los principios que la informan y sus dirigentes, como han dado en hacerlo los fieles servidores de Moscú, que más que la unidad del proletariado, lo que persiguen es imponer a éste un programa comunista importado de Rusias 52.

El Comité Nacional de Reconstrucción, y los sindicatos rojos partidarios de la ISR servirían de punta de lance para la preparación de la Conferencia Nacional de Unidad Sindical promovida por los comunistas. Su portavoz, Unidad Sindical, se volcará en fomentar la idea de unidad según los moldes de la IC.

Pero al mismo tiempo que se celebraba la Conferencia Nacional de Unidad Sindical (CNUS), en julio de 1932, el PCE mantenía vivo el Comité Nacional de Reconstrucción, lo que parecía una incongruencia denunciada en particular por $\mathrm{Nin}^{53}$.

Para lograr esta unidad, el PCE va a intentar un nuevo camino, crear su propia Central, la Confederación General del Trabajo Unitario (CGTU).

«Los Sindicatos adheridos a la ISR en su Conferencia del día 2 de julio [de 1932] han constituido un Comité Provisional que prepare un Congreso de todos los Sindicatos Rojos para la creación de la Conferencia General del Trabajo Unitario, que permita la unificación de toda la clase obrera bajo la plataforma de ia lucha de clases» ${ }^{54}$.

La duplicidad entre la CNUS y el Comité Nacional de Reconstrucción denota la existencia de una desorientación que confundía a los trabajadores. Todos estos esfuerzos tendían a organizar la CGTU que debía ser el Sindicato con el que soñaban los comunistas y que agruparía la mayoría de los trabajadores, bajo su influencia ideológica para implantar la revolución.

La creación de Consejo Central de Comités fue otra de las iniciativas del PCE para lograr alejar los trabajadores de las Centrales UGT y CNT. En Turón, se creó en septiembre de 1932, el Consejo Central de Comités de Mina de Turón, con representación de las minas «San Francisco», con 300 obreros, "San Benigno", con 400, "San Pedro" con 150, "Santo Tomas-Piedrafitas», con 200, «Polio» con 200, «Espinos" con 100, «Ortiz Sobrino» con 400, «Pedrizos» con $300{ }^{55}$. Fue el segundo Consejo Central

55 Frente Rojo, 17 de septiembre de 1932. 
de Comités que se constituía en España, después del de Sevilla. La aparición de varios organismos sindicales con denominaciones unitarias permitía crear confusión entre los trabajadores, y tenia como propósito, por una parte, promover la imagen de fuerza del PCE en el campo sindical, y por otra parte desprestigiar las Centrales existentes, y en particular sus dirigentes.

Antonio Mije fue el encargado, por parte de la dirección del PCE, de formalizar la creación de la CGTU. Definía el Congreso de la CGTU «no como el Congreso de un sector determinado de la clase obrera, sino que debe ser el Congreso de toda la clase obrera». El análisis simplista de la razón de ser de la CGTU era «que la CNT que era la fuerza mayor del movimiento sindical, está en descomposición, y la UGT tiene sus masas en rebeldía y llevan a la practica nuestras consignas" ${ }^{56}$.

Con la publicación de Frente Único, órgano central de la CGTU, se movilizó a los responsables del PCE para preparar un Congreso que debía mostrar su fuerza entre los trabajadores y presentar un frente sindical ante la CNT y UGT.

El papel de la CGTU era agrupar todos los sindicatos comunistas, entre ellos el SUM, y atraer los sindicatos autónomos presentando de esta manera un frente amplio para ser un interlocutor de peso frente a las demás Centrales Sindicales. Pero la fuerza sindical comunista se quedara muy por debajo de lo que disponían tanto la UGT como la CNT.

For otra parte, era difícil interpretar la diferencia que podía existir entre la CGTU y el CNUS, y fue necesaria la aclaración del CE del PCE.

"La carta de la IC y la política del Partido.

... llega la carta de la IC en la que se nos plantea el ir a la constitución de la CGTU con las fuerzas de los sindicatos del Comité de Reconstrucción y los sindicatos partidarios de la ISR. (...)

Con la carta de la ISR los campos quedan bien deslindados de forma que ahora los jefes de la UGT, de la CNT, del BOC no pueden llegar a esgrimir sus argumentos contrarios a la Unidad, escudado en justificaciones falsas de que la Conferencia de Unidad Sindical había de salir una nueva central sindical, que constituía un acto de escisión en el seno del proletariado de España, sino que tienen que aparecer ante los ojos de los obreros como verdaderos enemigos de la Unidad ya que queda descartado el que se llegue a constituir la nueva central de la Conferencia, como constantemente decían, puestos que los sindicatos partidarios de la ISR y el Comité de Renovación

56 Frente Único; 15 de julio de 1933. 
pasaban a organizarse en CGTU y de la Conferencia de Unidad Sindical saldría el nombramiento de un Comité Nacional encargado de seguir luchando por la unificación de todos los obreros de España. Es decir, mas claro aun, los sindicatos dirigidos por los comunistas pasaban a ser organizados en un plano nacional en la CGTU y con ellos a convertirse en el centro revolucionario de todas las luchas de los obreros de la ciudad y del campo, y el Comité de Unidad dedicado a proseguir la labor de unificación y lucha para conquistar la mayoría de los obreros para el Congreso Nacional de Unidad Sindical, y no podía ya presentarse como una tercera central disfrazada" ${ }^{57}$.

Pero ni el PCE, ni la CGTU lograban implantar una sólida infraestructura sindical. La CNT y la UGT se mantenían con suficiente influencia en el mundo del trabajo, y no daban muestras de autodisolverse ni deseos de desaparecer. El 12 de junio de 1934, el Pleno del Comité Central del PCE volvía a insistir acerca de la Ejecutiva del PSOE para alcanzar el Frente Único, proponiendo pactar una tregua política, suspendiendo los ataques mutuos. Los socialistas respondieron proponiendo la unidad en las Alianzas Obreras, a lo que se oponían los comunistas porque «llevaban en su propia esencia una contradicción que anulaba su eficacia: la ausencia en esas Alianzas de los campesinos; la negativa, en el fondo, a reconocer a los campesinos como una de las fuerzas motrices de la revolución española».

Pero los imperativos de la IC modificaron estos planteamientos ${ }^{58}$, y el 11 de septiembre de 1934 el Comité Central del PCE decidió la adhesión a las Alianzas poniendo como condición la libertad de critica. Para los comunistas las Alianzas debían servir para promover los órganos de Frente único, y en este sentido justificaban su estrategia, aunque muchos militantes se mostraron desorientados frente al cambio de actitud. El CE tuvo que enviar circulares a todos los Comités Provinciales ${ }^{59}$ para explicar el nuevo posicionamiento que consideraban como «la consecuencia lógica de su táctica consecuente de Frente Único». Se pasó de los ataques verbales a las Alianzas, a considerarlas idénticas al Frente Único. Para eso, los comunistas intentaban incluir en las Alianzas, además de representantes de partidos y sindicatos, delegados de fabricas y de centros de trabajo y tener así mas influencia en las decisiones.

El Secretario general del Partido Comunista de España, José Díaz, en el mitin en el Monumental Cinema de Madrid, el 2 de junio de 1935, explicaba ${ }^{60}$ :

\footnotetext{
AHPCE, caja 135, carp. 13, “Informe del 8 de septiembre de 1932».

Ver Rafael Cruz, ob. cit.

AHPCE-F VII.

DiAz, José, Tres Años de lucha, Toulouse, 1947, pág. 19.
} 
«Antes de Octubre, camaradas, antes de las jornadas de Octubre, nosotros luchábamos, como ahora, por la unificación de las fuerzas obreras. Nuestro Partido se ha esforzado siempre por convencer a los demás sectores obreros de que ésta es la condición indispensable para el triunfo. Y ésta es una idea que queremos grabar muy bien, muy hondo en la conciencia de todos los trabajadores. [..] Esta era nuestra posición, antes de Octubre: Por eso ingresamos en las Alianzas Obreras aún a sabiendas de que no eran la expresión acabada y consecuente del Frente Único. Ingresamos en ellas, para transformarlas en verdaderas organizaciones de frente único de los obreros y campesinos. Pero no lo conseguimos con la amplitud que era necesario, por las resistencias de unos y las incomprensiones de otros. En Asturias, donde nuestro Partido había conseguido hacer penetrar profundamente entre las masas la idea del Frente Único, y donde los Comités de Frente Único de lucha tenían ya una tradición, las Alianzas Obreras se organizaron rápidamente, y en parte en el mismo curso de los combates, y así fue posible que en Asturias lograra el proletariado la victoria sobre el enemigo, mientras que en los demás sitios de España en que los órganos de Frente Único no estaban creados y desarrollados, la lucha no pudo alcanzar la misma extensión y profundidad.»

«Si queremos triunfar en todo el país, es preciso que el Frente Único sea una realidad, a que la unidad de acción, se imponga, que las Alianzas Obreras y Campesinas se creen y desarrollen en todo el país.»

Después del fracaso de la revolución de 1934, el PCE desarrolló sus actividades en contra de la represión y por la liberación de los presos, apelando a la unificación de las fuerzas antifascistas.

\section{UNIFICACIÓN DEL SUM CON EL SOMA}

El SUM, después de la escisión de los anarcosindicalistas, vio reducida su influencia entre los mineros. Continuó defendiendo la táctica de Frente Único por las bases que propugnaba el PCE y siguió las consignas de la IC que este ultimo transmitía. Con la nueva estructura del sindicato, a finales de 1932, trasladando las secciones en los lugares de trabajo, el SUM presentó un frente de acción que tuvo relieve en particular en Sama, Turón y San Martín del Rey Aurelio. Cada movimiento huelguístico veía como el SUM proponía la creación de un Comité de huelga donde si bien no tenían primacía, si quitaban peso al SOMA, por lo que este ultimo trataba por todos los medios de minimizar las actividades de estos comités. EI SUM supo mostrar coherencia revolucionaria en sus planteamientos, y fue una de las organizaciones que con mas rigor aplicó las consignas del Frente Único. A la largo del año 1933, los problemas de la crisis hullera se resolvían con acuerdos entre la Patronal y el SOMA. Los comunistas y los anarquistas no dudaron en denunciar tal política que se alejaba de los in- 
tereses propios de los mineros. EI SUM fue entonces un referente para estos, pero en el momento en que aparecía el PCE, con su postura incondicional a la IC, y la falta de continuidad en su línea política de su dirección se creaba desorientación en las bases y no permitía la consolidación de lideres capaces de orientar y dirigir las luchas de los mineros en función de las condiciones propias de la cuenca minera asturiana.

La falta de confianza de la CGTU, como la del CE del PCE, hacia la Federación de Asturias y el SUM, se hace patente cuando el 8 de septiembre de 1932 se propone constituir la Unión Regional de Sindicatos Mineros y para esto dispone el:

«Envió de un instructor a Asturias que será el encargado de preparar un Congreso regional sobre la base del Sindicato Único de Mineros para constituir la Unión Regional de Sindicatos de Asturias, afecta a la CGTU. Este Congreso se celebrara para la segunda decena de septiembre. Será hecho todo bajo la dirección de la CGTU. [.]

Lanzamiento por el Sindicato Minero de Asturias de una carta abierta a todos los mineros de España, en la que se plantea la necesidad de la jornada de 6 horas. En la que se haga ver el papel de los mineros en la situación que existe abocados a una guerra y todos los problemas candentes de la lucha revolucionaria del proletariado de la mina. Esta carta debe servir de tanteo y a modo de referéndum debe esperar la contestación inmediata del proletariado minero de España, y que puede servir de base para la convocación de un Congreso Nacional de Mineros, organizado y dirigido por la CGTU. Ayudar al Congreso de jóvenes Mineros" ${ }^{61}$.

La celebración del primero de mayo de 1933 fue ocasión, para comunistas y socialistas, para promover actos de llamamiento a la unidad. Sama de Langreo y Mieres fueron escenarios de actos conjuntos, mostrando como la idea de Frente Único, u otro movimiento que agrupase los trabajadores, era visto con agrado. Hechos como la separación de dirigentes comunistas como Benjamín Escobar serían los que debilitaban las organizaciones comunistas y el SUM en particular. Era difícil para el minero asturiano entender las actitudes de los dirigentes de la dirección de Madrid, con sus diferencias palaciegas u ideológicas que se extendían en el campo doctrinario, pero que se alejaban de sus condiciones reales de vida.

Acostumbrados a luchar por el mismo motivo, mejorar sus condiciones económicas y sociales, los mineros, comunista, socialista y anarquista,

61 AHPCE, Caja 135, carp. 5. 
vecinos y parientes muchas veces, veían que solo con la unidad de acción podían lograr éxito en sus reivindicaciones frente a la Patronal

EI SUM se adhirió a la CGTU, y constituyó una de su fuerza principal. En la preparación de su Congreso en 1933, se planteaba ${ }^{62}$ :

«1. Intensificar el trabajo de organización en los lugares de trabajo [.]

2. Realizar una amplia campaña de esclarecimiento y de divulgación de la CGTU como única organización sindical de lucha de clase.

$3 .^{\circ}$ Organización de la oposición sindical revolucionaria en el seno del SOMA[.]

4. Realizar una amplia campaña de reclutamiento entre los obreros inorganizados y aquellos que diariamente se separan del SOMA.

5. Constitución de Comités de Frente Único en todos los pozos."

La proclama de estos cinco puntos permite enfatizar por una parte la aplicación de las consignas de la dirección nacional del PCE, y por otra parte la rivalidad que siempre existía con el SOMA, tratando de arrancarle sus militantes y presentándole como en estado de crisis permanente.

Para la preparación de su Congreso, la CGTU acordó celebrar tres Conferencias nacionales de metalúrgicos, de obreros portuarios y de mineros ${ }^{63}$. Estos últimos eran objeto de una atención especial, y fue el SUM el encargado de la preparación de la Conferencia Nacional Minera.

A partir de 1934, se va asistir a otro cambio de estrategia de los comunistas en el campo sindical, en particular en lo que refiere a los temas de unidad. Se eliminaron los ataques directos a los dirigentes de las demás centrales sindicales, se ignoró la "absorción unitaria» dentro de la CGTU, y se suavizó (los tics adquiridos no llegaran a eliminarse totalmente, y se podrá leer los calificativos de «Judas socialistas» ó «renegados del SOMA» ${ }^{64}$ ) los comentarios despreciativos hacia la UGT y CNT.

El Congreso del SUM en marzo de 1934, no contenía en su orden del día intromisión alguna con los demás sindicatos como se acostumbraba hacer. Los cuestiones que en él se debatieron se centraron en la CGTU. En el Congreso Provincial de los Sindicatos Rojos de Asturias los 21, 22 y 23 de julio de 1934, se discutieron también los asuntos propios a CGTU ${ }^{65}$.

\footnotetext{
62 Frente Único, 18 de julio de 1933.

63 Frente Único, 5 de agosto de 1933.

64 Frente Único, 23 de febrero de 1934, «Hacia la unidad de acción en las minas».

65 Frente Único, 30 de julio de 1934. «La CGTU en Asturias».
} 
El 15 de agosto de 1934, Antonio Mije, como secretario general y en nombre del Buró de la CGTU, hacía otro llamamiento a la Comisiórı Ejecutiva de la UGT para «lograr la unidad de acción para objetivos concretos y que puede significar un punto de partida para pasar a gestiones directas que en un porvenir próximo nos lleven a lograr la unificación sindical del proletariado en una sola central» ${ }^{66}$. Anteriormente, el 25 de julio ya se había cursado otra carta que no tuvo contestación.

La revolución de Octubre tuvo como efecto, por parte del PCE, insistir aún más en la unidad con las demás fuerzas obreras ${ }^{67}$, en especial con el PSOE. Las campañas contra la represión, por la liberación de los presos y la unificación de las fuerzas antifascistas fueron el eje de sus planteamientos.

Pero el PCE pretendía ir mucho más allá en la unidad de acción. Así pues, el 26 de noviembre de 1934, envió una carta a la Ejecutiva del PSOE para la creación de Comités de enlace ${ }^{68}$. Estos Comités se superponían a las Alianzas Obreras y en realidad no fueron muy efectivos. La fusión orgánica se quedaba en planteamientos teóricos que se concreto en parte en Asturias con la iniciativa de un Frente Único Marxista. Finalmente se combinaba Frente Único por abajo con la Alianza Obrera en los lugares de trabajo, con Comités de enlace y unidad de acción por arriba, a los que abría que añadir en el año 1935 la Concentración Popular Antifascista con llamamiento a la unidad de los trabajadores de todas las clases.

A lo largo del año 1935, estaba claro, tanto para el PCE como para la CGTU, que a pesar de todos los intentos para dominar el mundo sindical su fuerza en el ámbito nacional era muy escueta. Abandonando los intentos de unidad con la CNT que había sido a lo largo de los últimos años su sindicato más afín, los comunistas de mano de la CGTU se volcaron hacia la UGT para lograr lo que llamaran una fusión pero que en realidad fue una integración.

Durante el año de 1935 tanto los partidos obreros como los sindicatos vieron como sus actividades adquirían un carácter unitario. Los calificativos mutuos eran más cordiales y las bases se manifestaban conjuntamente.

66 Frente Único, 15 de agosto de 1934. «La CGTU insiste nuevamente cerca de la UGT».

67 AHPCE, sig. 5 y 10, pág. 88: «1934 ocupa un lugar destacado en la historia de la lucha de nuestro pueblo contra el fascismo y no solo por su heroico levantamiento armado, sino porque en él se inicio el camino de la clase obrera hacia la unidad de acción.»

68 Díaz José, «A la Comisión Ejecutiva del Partido Socialista», 29 de noviembre de 1934. 
La correspondencia de los días 8 y 15 de noviembre entre la UGT y la CGTU daba cuenta de los acuerdos a los que habían llegado las dos centrales, y exponía las instrucciones para llevar a la practica dicha fusión. Para esto se pedía el ingreso en bloque de todos los militantes, y "en el caso de ser ambas fuerzas niveladas o superiores las nuestras", debía celebrarse una asamblea del sindicato unificado para elegir la nueva dirección. En cuanto al SUM se indicaba claramente que éste se integraría en el SOMA, y que se celebraría un Congreso para elegir la nueva dirección. Finalmente se hacía un llamamiento para que dicha fusión vaya acompañada de propaganda conjunta entre socialistas y comunistas, organizando mítines y Asambleas conjuntas.

El 22 de noviembre de 1935, el Comité Nacional de la CGTU enviaba «A todas nuestras organizaciones y simpatizantes» una nota en la que destacaban ${ }^{69}$ :

«Nuestros continuados esfuerzos en pro de la realización de la unidad sindical, toda la actividad desplegada por nuestras organizaciones y militantes en este sentido, abocan ya a resultados positivos. Hoy podemos dar a todas nuestras organizaciones y militantes y a todos los obreros en general la grata noticia de que, después de una serie de gestiones y proposiciones, hemos llegado con la Comisión Ejecutiva de la UGT a un punto de coincidencia para la realización de la fusión entre ambas organizaciones. ”

El 21 de diciembre de 1935 relatando el estado de fusión CGTU y UGT, se indicaba ${ }^{70}$ :

«ASTURIAS: El Sindicato Único de Mineros (CGTU) y el Sindicato Minero Asturiano (UGT) han establecido un acuerdo para la fusión. En las secciones de base (de mina, locales, etc.) la dirección será nombrada democráticamente. En los Comités Comarcales y en la dirección central se renovaran los cargos del SMA a medida que puedan celebrarse las reuniones."

Se dice en la misma nota:

«Esperamos que la total fusión de la CGTU y la UGT quede realizada, a mas tardar, hacia mediados del próximo mes de enero.»

Los militantes del SUM se integraron en el SOMA. Éste agrupó prácticamente a todos los mineros y vio crecer aún más su influencia en la

69 AHPCE, caja 135, carp. 5.

70 AHPCE, caja 135 , carp. 5 
cuenca minera. Se mantuvo el Sindicato Único de los anarquistas, siempre afiliado a la CNT, utilizando en 1937 tanto la denominación SUM (CNT) ó SUM, Comité de Relaciones ${ }^{71}$.

\section{CONCLUSIONES}

Frente a una Patronal organizada para defender sus intereses, los obreros intentaron mejorar sus pésimas condiciones de vida y emprendieron movimientos reivindicativos de manera desordenada que se traducían por una serie de fracasos, con el desánimo correspondiente.

En 1910, con la creación del SOMA, Llaneza al frente, los mineros empezaron un historial de luchas, con altos y bajos, pero de eficacia y de respeto. La Patronal fundó entonces, en 1913, la Asociación Patronal de Mineros Asturianos quien será la que llevaría las negociaciones con el SOMA a lo largo de los numerosos movimientos sociales.

La situación internacional, política y económica, fue un factor que ayudó a la aparición de la organización obrera. La revolución rusa constituyó un aliciente y un horizonte para la clase obrera española. Si bien había diferentes interpretaciones sobre aquellos acontecimientos por parte de los dirigentes comunistas, socialistas y anarquistas, para las bases obreras predominaban admiración y ejemplo. Eso explica la actitud de los mineros a lo largo de los numerosos Congresos del SOMA en 1922. No estaban dispuestos a renunciar al movimiento huelguístico ya que era su principal arma para enfrentarse a la Patronal. Esta última jugó un papel importante para la división de los mineros. Su actitud intransigente, prepotente y arrogante era considerada como provocadora por los mineros. Se comportó con espíritu de clase al mismo tiempo que negaba la lucha de clases y llamaba a la solidaridad para mantener sus privilegios. Así era la mentalidad de unos empresarios que no supieron desarrollar la actividad económica, o que interpretaban esa como la creación de beneficios personales y no de riqueza nacional. Nació entonces el SUM, un sindicato minero situado a la izquierda del sindicato socialista. También es necesario subrayar el papel del propio Llaneza en la escisión del SOMA y la creación del SUM. No cabe duda que sus relaciones con los comunistas eran poco cordiales. Su oposición a la III Internacional era clara y no dejaba ninguna posibilidad de entendimiento. Por otra parte su fuerte personalidad

71 Archivo Histórico Nacional, Guerra Civil (AHNGC), K227. 
no permitía intromisión alguna en sus planteamientos. No podía admitir que su trabajo al frente del SOMA pudiese quedar en manos de los comunistas. Maniobró con éxito e inteligencia para que la dirección no se le fuera de las manos, pero su comportamiento hacia los comunistas fue de puro enfrentamiento, particularmente a raíz de la perdida de la secretaria en 1921. Finalmente hay que destacar la actitud de los comunistas. Aquí hay que diferenciar la Dirección de Madrid, donde las órdenes de la IC eran transmitidas a las direcciones provinciales, sin más, y la Federación Comunista de Asturias quien trataba de adaptar las consignas a la realidad $^{72}$. No era fácil conseguirlo, y esta posición creaba relaciones tensas entre Madrid y Oviedo.

Los mineros comunistas, apoyados por los anarquistas, a quien habían integrado en el Sindicato Minero, representaban el ala más revolucionaria, mas decidida de los trabajadores de la cuenca minera. Su respeto entre los demás mineros era reconocido, y su abnegación e integridad constituían un atractivo para participar en los movimientos reivindicativos que promovían. Su salida del SOMA y la creación del SUM, fue sin duda un error, pero... ¿tenían otra alternativa?

Con la consigna «Ni un céntimo menos, ni un minuto más» de 1922, el SUM supo encauzar las aspiraciones de los mineros. Pero fue sin duda la huelga de 1927 la que arrastró mayor simpatía hacia sus militantes. A pesar de la violenta represión por parte del Gobierno, aquella huelga atrajo hacia sus filas militantes del SOMA.

En 1932, con la celebración de la Conferencia Nacional de Unidad Sindical, el PCE intentó dinamizar el problema sindical, promoviendo un Comité Nacional de Unidad Sindical para cluchar por la unificación de todos los obreros de España», y constituyendo la Confederación General del Trabajo Unitario que aglutinaría a todos los sindicatos partidarios de la ISR. Las consignas de Frente Único y de Unidad se diluían en actuaciones que debilitaron los esfuerzos de los militantes.

72 Es curioso como el Comité Ejecutivo del PCE a través del Secretariado del CN de Reconstrucción culpaba al SUM de los fracasos, y las criticas que exponia eran mas bien autocríticas que hubiesen tenido que hacerse. Así escribian: «EI SUM por falta de ligazón con la base no ha sabido interpretar bien en su política las reivindicaciones de las masas de obreros mineros. En su programa reivindicativo, al lado de las consignas comunes a toda clase trabajadora no figuran las reivindicaciones inmediatas especificas de los trabajadores del subsuelo, y el ultimo Congreso no ha podido corregir esta falta importante. [.] Existe en los cuadros dirigentes del sindicato un gran temor al método revolucionario de la autocrítica que los militantes responsables del Sindicato no han aprendido a considerar como la mejor manera de rectificar los errores." Unidad Sindical, «Resolución del Secretariado del CN de Reconstrucción sobre la actuación del Sindicato Único Minero de Asturias», 17 de mayo de 1932. 
EI SUM tardaría diez años, desde su creación, en adherirse a la ISR, y sólo tres años después se fusionó con el SOMA. No se puede decir que disfrutaba de la confianza de los responsables políticos del PCE. El recelo era mutuo, y sólo «la fe hacia la revolución rusa» lograba que se mantuvieran relaciones orgánicas. Los vaivenes de la política sindical de una dirección del PCE que no supo definir sus propias estrategias sindicales terminó con la mayor organización obrera comunista. 